\title{
Dyslipidemia and Mortality in Young Patients Victims Of Cerebral Vascular Accident
}

\section{Mohamed Lelouma Mansare ${ }^{1,2 *}$, Kamadore Toure ${ }^{1}$, Moustapha Ndiaye $^{1}$ and Amadou Gallo Diop ${ }^{1}$}

${ }^{1}$ Department of Neurology, FANN Teaching Hospital, Dakar, Senegal

${ }^{2}$ Department of Neurology, Donka Teaching Hospital, Conakry, Guinea

*Corresponding Author: Mohamed Lelouma Mansare, Department of Neurology, FANN Teaching Hospital, Dakar, Senegal.
Received: July 27, 2021

Published: September 22, 2021

(C) All rights are reserved by Mohamed

Lelouma Mansare., et al.

\begin{abstract}
The risk of developing a vascular event attributable to dyslipidemia is correlated with the time of exposure to abnormally high levels of cholesterols in the blood. The occurrence of this event can compromise the survival of patients. The aim of this study was to determine the death rate among young patients hospitalized for Cerebral Vascular Accident in whom dyslipidemia had been observed. The study was carried out for two years.

Among the 609 cases of Cerebral Vascular Accident, 76 patients were between 16 and 45 years of age. They were grouped into two categories: those who presented with cerebral infarctions and those who presented with non-traumatic cerebral hemorrhages. Lipid profiles were analyzed. The cholesterol levels (C-g/l) with the following values (C-T $\geq 2.4 ; \mathrm{C}-\mathrm{LDL} \geq 1.6$; C-HDL $<0.4$ and Triglycerides $\geq 1.5$ ) were considered abnormal. The death rate was calculated by category of Cerebral Vascular Accident.

Cerebral infarctions were the most predominant. The highest cumulative mortality rate (20/27) was observed in the age group of 36-45 years for the two Cerebral Vascular Accident categories. This age group corresponds to the economically productive population.

HDL-c fraction dyslipidemia is not uncommon in young people. High rates of mortality were observed in young normally active patients who presented with dyslipidemia, sedentary lifestyle and obesity. Carrying out recommended sports activities can help to significantly reduce the occurrence of vascular events to the brain.
\end{abstract}

Keywords: Cerebral Vascular Accident; Mortality; Dyslipidemia

\section{Abbreviations}

CVA: Cerebral Vascular Accident; NA: Not Applicable; TC: Total Cholesterol; HDL: High Density Lipoprotein; LDL: Low Density Lipoprotein; TG: Triglycerides; CI: Confidence Interval; AHT: Arterial Hypertension; OR: Odds Ratio.

Legends

Sedentary lifestyle $=$ regular physical activities less than 2 hours per week;

Fat meal * = to eat at least one fatty meal/day;
Tobacco $^{* *}=$ to smoke at least 1 cigarette/day;

Alcohol ${ }^{* * *}=$ to consume at least 1 glass of beer/day;

Obesity ${ }^{* * * *}=$ Body Mass Index $>30$.

\section{Introduction}

Cerebral Vascular Accident (Stroke) is being a leading cause of early death and acquired disability worldwide. This trend is well observed in low- and middle-income countries as it is in high-income countries [1,2]. There are two major vascular risk factors associated with stroke: Modifiable risk factors, such as: arterial 
hypertension (hypertension), diabetes, tobacco, dyslipidemia, sedentary lifestyle, fatty meals, alcohol, obesity and those. Non-modifiable risk factors, that in particular include age and sex. The risk of developing a vascular event attributable to dyslipidemia is correlated with the time of exposure to abnormally high levels of cholesterols in the blood [3-6]. The occurrence of this event can compromise the survival of patients.

\section{Methodology}

The aim of this study was to determine the risk factors, prevalence and death rate for Cerebral Vascular Accident in hospitalized young patients with dyslipidemia. A total of 609 cases of stroke were collected over two years (2013-2014) in Senegal and among them 76 patients were aged between 16 to 45 years. These patients were divided into three age groups. They were also grouped into two categories: Patients with cerebral infarction (58 cases) and those with non-traumatic cerebral hemorrhages (18 cases). Their lipid profiles were analyzed and the Cholesterol levels were considered as abnormal if $\mathrm{C}-\mathrm{T} \geq 2.4 ; \mathrm{C}$-LDL $\geq 1.6$; $\mathrm{C}$-HDL $<0.4$ and Triglycerides $\geq 1.5$. The mortality rate was calculated in relation to all vascular risk factors that were incriminated in the occurrence of stroke. Mainly, these risk factors included: age, sex, physical inactivity, fatty meals, hypertension, diabetes, tobacco, dyslipidemia, alcohol and obesity.

Statistical analysis of the data was performed using IBM SPSS Statistics version 23 software to assess the prevalence and death rate. The risk of error was estimated at $5 \%$.

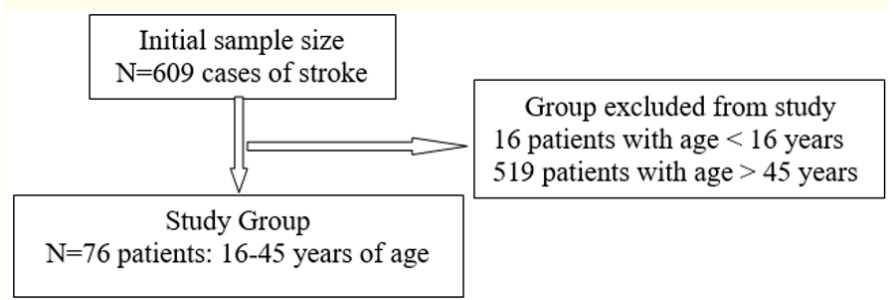

Figure 1: Patients recruitment diagram.

\section{Results}

\section{Characteristics of patients}

The study population included 35 women aged between 18 and 35 years and 41 men aged between 16 and 45 years. The two forms of stroke were observed in majority in the men in this series, that is to say 30 cases $(39.5 \%)$ of infarction against 11 cases $(14.5 \%)$ of hemorrhage.

Prevalence of vascular risk factors associated with stroke (see table 1)

The study's results indicated that the modifiable vascular risk factors were independently associated with the types of stroke. The prevalence for the hemorrhagic factors were: tobacco 17 (22.4\%); sedentary lifestyle 16 (21\%); obesity 13 (17.1\%); HTA 9 (11.2\%); alcohol 7 (9.2\%) and diabetes 2 (2.6\%); while it was for the infarction: hypertension 49 (64.5\%); the fatty meal 42 (55.2\%); sedentary lifestyle 38 (50\%); obesity 34 (44.7\%); tobacco (26.3\%); diabetes 10 (13.2\%) and alcohol 1 (1.3\%). HDL-cholesterol-fraction dyslipidemia was predominantly observed in both types, 22 (28.9\%) for cerebral infarction and 7 (9.2\%) for cerebral hemorrhage.

\begin{tabular}{|c|c|c|c|c|}
\hline \multirow{2}{*}{\multicolumn{2}{|c|}{$\begin{array}{c}\text { Vascular Risk Factor } \\
\text { Hemorrhage: } 18 \\
(23.7 \%)\end{array}$}} & \multicolumn{2}{|c|}{ Case of CVA } & \multirow{3}{*}{$\begin{array}{c}\text { Total: } 76 \\
\begin{array}{c}\text { (100\%) } \\
7(9.2)\end{array}\end{array}$} \\
\hline & & \multirow{2}{*}{$\begin{array}{c}\begin{array}{c}\text { Infarc- } \\
\text { tion: } 58 \\
(76.3 \%)\end{array} \\
1(1.3) \\
\end{array}$} & \multirow[b]{2}{*}{$6(7.9)$} & \\
\hline \multirow[t]{3}{*}{ Age (years) } & $16-25$ & & & \\
\hline & $26-35$ & $4(5.3)$ & $19(25.0)$ & $23(30.3)$ \\
\hline & $36-45$ & $13(17.1)$ & $33(43.4)$ & $46(60.5)$ \\
\hline \multirow[t]{2}{*}{ Sex } & $\mathrm{F}$ & $7(7.2)$ & $28(36.8)$ & $35(46.0)$ \\
\hline & M & $11(14.5)$ & $30(39.5)$ & $41(54.0)$ \\
\hline \multicolumn{2}{|c|}{ Sedentary lifestyle } & $16(21.0)$ & $38(50.0)$ & $54(71.0)$ \\
\hline \multicolumn{2}{|c|}{ Fatty meal * } & $11(14.5)$ & $42(55.2)$ & $53(69.7)$ \\
\hline \multicolumn{2}{|c|}{ AHT } & $9(11.8)$ & $49(64.5)$ & $58(76.3)$ \\
\hline \multicolumn{2}{|c|}{ Type II Diabetes } & $2(2.6)$ & $10(13.2)$ & $12(15.8)$ \\
\hline \multicolumn{2}{|c|}{ Tobacco** $^{* *}$} & $17(22.4)$ & $20(26.3)$ & $37(48.7)$ \\
\hline \multirow{4}{*}{$\begin{array}{l}\text { Dyslipid- } \\
\text { emia (g/l) }\end{array}$} & $\mathrm{TC} \geq 2.4$ & $2(2.6)$ & $6(7.9)$ & $8(10.5)$ \\
\hline & $\mathrm{LDL} \geq 1.6$ & $3(3.9)$ & $5(6.6)$ & $8(10.5)$ \\
\hline & $\mathrm{HDL}<0.4$ & $7(9.2)$ & $22(28.9)$ & $29(38.1)$ \\
\hline & $\mathrm{TG} \geq 1.5$ & NA & $6(7.9)$ & $6(7.9)$ \\
\hline \multicolumn{2}{|c|}{ Alcohol*** } & $7(9.2)$ & $1(1.3)$ & $8(10.5)$ \\
\hline \multicolumn{2}{|c|}{ Obesity $* * * *$} & $13(17.1)$ & $34(44.7)$ & $47(61.8)$ \\
\hline
\end{tabular}

Table 1: Prevalence of vascular risk factors associated with stroke $(\mathrm{N}=76)$. 
Morbidity and vascular risk factors associated with stroke (see table 2)

The majority of study's patients (74.4\%) aged between 36 and 45 years died. Among deceased women, $48.2 \%$ had cerebral infarction and $14.8 \%$ had cerebral hemorrhage. Among deceased patients who presented with cerebral infarction (51.9\%), the HDL-cholesterol fraction dyslipidemia was observed in 59.3\%. Other associated vascular risk factors such as sedentary lifestyle and obesity were reported in $81.5 \%$ of cases and $70.4 \%$ of cases respectively.

\begin{tabular}{|c|c|c|c|c|}
\hline \multicolumn{2}{|c|}{$\begin{array}{c}\text { Vascular Risk } \\
\text { Factors }\end{array}$} & \multicolumn{3}{|c|}{ Morbidity (VCA) } \\
\hline & & $\begin{array}{c}\text { Hemorrhage : } \\
5(18.5 \%)\end{array}$ & $\begin{array}{l}\text { Infarction : } \\
22(81.5 \%)\end{array}$ & $\begin{array}{c}\text { Total } \\
27(100 \%)\end{array}$ \\
\hline \multirow{3}{*}{$\begin{array}{c}\text { Age } \\
\text { (years) }\end{array}$} & $16-25$ & NA & $2(7.4)$ & $2(7.4)$ \\
\hline & $26-35$ & NA & $5(18.5)$ & $5(18.5)$ \\
\hline & $36-45$ & $5(18.5)$ & $15(55.6)$ & $20(74.1)$ \\
\hline \multirow[t]{2}{*}{ Sex } & $\mathrm{F}$ & $1(3.7)$ & $13(48.2)$ & $14(51.9)$ \\
\hline & M & $4(14.8)$ & $9(33.3)$ & $13(48.1)$ \\
\hline \multicolumn{2}{|c|}{ Sedentary lifestyle } & $5(18.5)$ & $17(63.0)$ & $22(81.5)$ \\
\hline \multicolumn{2}{|c|}{ Fatty meal* } & $2(7.4)$ & $7(25.9)$ & $9(33.3)$ \\
\hline \multicolumn{2}{|c|}{ AHT } & $1(3.7)$ & $13(48.2)$ & $14(51.9)$ \\
\hline \multicolumn{2}{|c|}{ Type II Diabetes } & NA & $5(18.5)$ & $5(18.5)$ \\
\hline \multicolumn{2}{|c|}{ Tobacco** } & $2(7.4)$ & $9(33.3)$ & $11(40.7)$ \\
\hline \multirow{4}{*}{$\begin{array}{c}\text { Dyslipi- } \\
\text { demia } \\
\text { (g/l) }\end{array}$} & $\mathrm{TC} \geq 2.4$ & $1(3.7)$ & $1(3.7)$ & $2(7.4)$ \\
\hline & $\begin{array}{c}\mathrm{LDL} \geq \\
1.6\end{array}$ & $2(7.4)$ & $1(3.7)$ & $3(11.1)$ \\
\hline & $\begin{array}{c}\mathrm{HDL}< \\
0.4\end{array}$ & $2(7.4)$ & $14(51.9)$ & $16(59.3)$ \\
\hline & $\mathrm{TG} \geq 1.5$ & NA & $2(7.4)$ & $2(7.4)$ \\
\hline \multicolumn{2}{|c|}{ Alcohol*** } & $3(11.1)$ & NA & $3(11.1)$ \\
\hline \multicolumn{2}{|c|}{ Obesity ${ }^{* * * *}$} & $5(18.5)$ & $14(51.9)$ & $19(70.4)$ \\
\hline
\end{tabular}

Table 2: Morbidity and vascular risk factors associated with stroke $(\mathrm{N}=27)$.

Mortality by age group according to the type of stroke with dyslipidemia (see table 3 )

All of the deceased patients (36-45 years of age) had presented with dyslipidemia. The majority of them were victims from cerebral infarction. Other than this age group, no death was observed in the other groups with cerebral hemorrhage.

\begin{tabular}{|c|c|c|c|c|c|c|}
\hline \multirow{2}{*}{$\begin{array}{c}\begin{array}{c}\text { Type of } \\
\text { Stroke } \\
\text { (76cas) }\end{array} \\
\begin{array}{c}\text { Age group } \\
\text { (year) }\end{array} \\
\text { (76 cases) }\end{array}$} & \multicolumn{3}{|c|}{$\begin{array}{c}\text { Hemorrhage } \\
\text { (18 cases) }\end{array}$} & \multicolumn{3}{|c|}{$\begin{array}{l}\text { Infarction } \\
\text { (58 cases) }\end{array}$} \\
\hline & $\begin{array}{c}16-25 \\
(1)\end{array}$ & $\begin{array}{c}26-35 \\
(4)\end{array}$ & $\begin{array}{c}36-45 \\
(13)\end{array}$ & $\begin{array}{c}16-25 \\
(6)\end{array}$ & $\begin{array}{c}26-35 \\
(19)\end{array}$ & $\begin{array}{c}36-45 \\
(33)\end{array}$ \\
\hline $\begin{array}{c}\text { Deceased } \\
\text { (27 cases) }\end{array}$ & - & - & $5 / 13$ & $2 / 6$ & $5 / 19$ & $15 / 33$ \\
\hline \multicolumn{7}{|c|}{ Dyslipidemia g/l (case) } \\
\hline $\mathrm{TC} \geq 2,4(2)$ & - & - & $1 / 5$ & - & - & $1 / 15$ \\
\hline $\mathrm{LDL} \geq 1,6(3)$ & - & - & $2 / 5$ & - & - & $1 / 15$ \\
\hline $\begin{array}{c}\mathrm{HDL}<0,4 \\
(16)\end{array}$ & - & - & $2 / 5$ & $1 / 2$ & $4 / 5$ & $9 / 15$ \\
\hline $\mathrm{TG} \geq 1,5(2)$ & - & - & - & - & - & $2 / 15$ \\
\hline
\end{tabular}

Table 3: Mortality by age group and by type of stroke with dyslipidemia $(\mathrm{N}=27 / 76)$.

\section{Discussion}

The prevalence of stroke increased with age regardless of the type. In the study population, 35 women were aged between 18 and 35 years and 41 men were between 16 and 45 years of age. Cerebral infarctions was observed in $76.3 \%$ of cases and cerebral hemorrhages in $23.7 \%$.

The two forms of stroke were mostly observed among the men with $39.5 \%$ for infarction against $14.5 \%$ for hemorrhage. The results of the study indicated the following prevalence for the risk factors associated with modifiable vascular risk factors analyzed associated with stroke.

The results of this series suggest that the prevalence of modifiable vascular risk factors associated with stroke were respectively:

- Hemorrhagic type: Tobacco (22.4\%); sedentary lifestyle (21\%); obesity (17.1\%); HTA (11.2\%); alcohol (9.2\%) and diabetes $(2.6 \%)$.

- Infarction: Hypertension (64.5\%); fatty meal (55.2\%); sedentary lifestyle (50\%); obesity (44.7\%); tobacco (26.3\%); diabetes (13.2\%) and alcohol (1.3\%).

HDL-cholesterol-fraction dyslipidemia was mainly observed in both types: Cerebral infarction (28.9\%) and cerebral hemorrhage 
(9.2\%) (See Table 1). In a study carried out in the USA [7], the authors had collected national data from a sample of 4,438, 698 patients hospitalized for stroke between 2004 and 2014. They calculated the weighted prevalence of each cardiovascular risk factor by using junction point regression model to assess changes in prevalence over time. The weighted adjusted prevalence $(P=0.001)$ of cardiovascular risk factors in stroke patients during this period was for: hypertension 79.1\%; Diabetes II, 33.9\%; dyslipidemia, 46.9\%; tobacco, $15.1 \%$; alcohol, $3.2 \%$ and obesity, $7.8 \%$. The mean annual change for dyslipidemia was $6.9 \%(\mathrm{CI}=6.2-7.7$; $\mathrm{P}<0.05$ ). The estimated odds ratio (OR) of dyslipidemia for the age group 40-59 vs $18-39$ was 1.49 ( $\mathrm{CI}=1.45-1.52$; $\mathrm{P}=0.001)$.

The majority of the patients aged between 36 and 45 years in that study had died 20 (74.4\%). This age group corresponds to the economically productive working population compared to the age group of 26-35 years. The majority of deceased women had cerebral infarction (48.2\%) while $14.8 \%$ of the deceased men had experienced cerebral hemorrhage. HDL-cholesterol-fraction dyslipidemia was predominant in the deceased patients with cerebral infarction (51.9\%). Among the other associated vascular risk factors, sedentary lifestyle was the most notified (81.5\%) in young patients (Table 2). All of the deceased patients at age between 36 and-45 years had dyslipidemia. Apart from this age-group, no case of death was observed in the other groups with cerebral hemorrhage (Table 3). This result suggests that the occurrence of death was not related to the types of stroke but to age. Exceptionally, HDL-cholesterol dyslipidemia was observed in all age groups in the study. In a study [8] of data from 11 registers in Europe and America relating to the specific analysis (Cox regression and KaplanMeier product) for age and sex in patients with an embolic stroke of unknown source, the authors reported that age, and not gender, was an important predictor for the recurrence of fatal strokes. In that study, female sex was not associated with an increased risk of stroke. The risk was 3 and 8 times higher in patients 80 years old compared to those 60 years old respectively. In the USA, Roger Chou., et al. [9] had analyzed 352 full-text articles on the value of screening or treating asymptomatic dyslipidemia in young adults aged 21 to 39 years by evaluating the risk of mortality, cardiovascular disease, morbidity or mortality related to stroke. Jagat P S., et al. [10] reported in their case-control study $13.72 \%$ (14 cases) of death among the 102 recurrent stroke cases. Of these, $71.42 \%$ (10 cases) had dyslipidemia. They pointed out that the decrease in HDL cholesterol would be the main factor for the occurrence of fatal vascular events.

Scientific observations from the Ancient Greece have indicated that obese people tend to die younger than thin ones. In today's constantly changing world, it is likely that the demands for economic profitability may force young workers to become sedentary. They no longer go to the restaurant on foot, they order by "on site-delivery". Also, changes in eating behavior, such as having fatty meals, are other corollaries of the change in culinary habits in the recent decades. The latter may also be another additional influencing risk factor involved in the occurrence of vascular events. When these determinants of health are poorly controlled, they can destabilize the state of health of individuals by compromising their functional and survival prognoses.

\section{Conclusion}

HDL-c fraction dyslipidemia is not uncommon in young people. The majority of patients who died in our study showed significant lowering of HDL-cholesterol levels in both types of stroke. High mortality rates were observed in normally active youth who presented with dyslipidemia associated with sedentary lifestyle and obesity. The best way to bypass the bad consequences of our eating behavior on our life is to have adequate diet with the objective of calorie restriction by limiting the quantity of food but not the quality. Regularly performing the recommended sports activities and consuming less fatty meals could significantly reduce the occurrence of fatal vascular events in young people.

\section{Conflict of Interest}

Declared none.

\section{Bibliography}

1. Sachin S., et al. "Clinical study of acute stroke with special reference to Greek Stroke Scoring System”. International Journal of Research in Medical Sciences 5.3 (2017): 927-936.

2. To'th PP., et al. "Prevalence of lipid abnormalities in the United States: the National Health and Nutrition Examination Survey 2003-2006". Journal of Clinical Lipidology 6 (2012): 325-330.

3. Expert Panel on Detection, Evaluation, and Treatment of High Blood Cholesterol in Adults. "Executive Summary of the Third Report of the National Cholesterol Education Program (NCEP) (Adult Treatment Panel III)". JAMA 285.19 (2001): 2486-2497. 
4. Mihaylova B., et al. "The effects of lowering LDL cholesterol with statin therapy in people at people at low risk of vascular disease: meta-analysis of individual data from randomized trials". Lancet 380 (2012): 581-590.

5. Castelli WP., et al. "Lipids and risk of coronary heart disease. The Framingham Study". Annals of Epidemiology 2 (1992): 2328.

6. Stamler J., et al. "Is relationship between serum cholesterol and risk of premature death from coronary heart disease continuous and graded? Findings in 356,222 primary screenees of the Multiple Risk Factor Intervention Trial (MRFIT)". JAMA 256 (1986): 2823-2828.

7. F O Otite., et al. "Increasing prevalence of vascular risk factors in patients with stroke: A call to action". Neurology (AAN) 89.19 (2017): 1985-1995.

8. Ntaios George., et al. "Age- and sex-specific analysis of patients with embolic stroke of undetermined source". Neurology 89.8 (2017): 1-8.

9. Roger Chou., et al. "Screening for Dyslipidemia in Younger Adults: A Systematic Review for the U.S. Preventive Services Task Force". Annals of Internal Medicine 165.8 (2016): 560564.

10. Jagat Pal Singh and Sapna Nagvanshi. "Prospective Cross Sectional Study of Incidence and Correlation of Dyslipidemia in Predicting Outcome of Patients Diagnosed with Cerebrovascular Accident". International Journal of Contemporary Medical Research 4.6 (2017): 77-83.

Volume 5 Issue 10 October 2021

(C) All rights are reserved by Mohamed Lelouma

Mansare., et al.

Citation: Mohamed Lelouma Mansare., et al. "Dyslipidemia and Mortality in Young Patients Victims Of Cerebral Vascular Accident". Acta Scientific Medical Sciences 5.10 (2021): 120-124. 